\title{
Nitric Oxide Involvement in Bermudagrass Response to Salt Stress
}

\author{
Ao Liu and Jibiao Fan \\ Key Laboratory of Plant Germplasm Enhancement and Specialty Agriculture and Wuhan Botanical \\ Garden, Chinese Academy of Sciences, Wuhan, Hubei 430074, China; and University of Chinese \\ Academy of Sciences, 19 Yuquan Road, Beijing 100049, China \\ Margaret Mukami Gitau, Liang Chen ${ }^{1}$, and Jinmin Fu ${ }^{1}$ \\ Key Laboratory of Plant Germplasm Enhancement and Specialty Agriculture and Wuhan Botanical \\ Garden, Chinese Academy of Sciences, Wuhan, Hubei 430074, China
}

\begin{abstract}
AdDitional Index words. Cynodon dactylon, high salinity, NO, antioxidant defense systems, photosynthesis system, ionic balance

Abstract. Bermudagrass [Cynodon dactylon (L.) Pers.] is a warm-season turfgrass that has the potential to improve saline and alkaline soils. However, its utilization is severely limited by high salinity. Therefore, it is urgent to enhance its tolerance to salt stress. Previous studies have proved that nitric oxide (NO) plays a vital role in various biological processes. However, the role of NO in bermudagrass response to salt is unknown. Our objective here was to investigate whether and how NO contributes to the protection of bermudagrass against salt stress in bermudagrass. In this study, sodium nitroprusside (SNP) served as the NO donor, while 2-phenyl-4,4,5,5-tetramentylimidazoline-l-oxyl-3-xide (PTIO) plus NG-nitro-L-arginine methyl ester (L-NAME) acted as the NO inhibitor. The treatment of bermudagrass with 400 mм salt solution occurred under different regimes: control, SNP, PTIO + L-NAME (PL). The results showed that $400 \mathrm{~mm}$ salinity caused significant toxicity to bermudagrass. However, SNP alleviated damage effect on plant growth and ionic balance as indicated by higher water content, chlorophyll content, higher chlorophyll $a$ fluorescence (OJIP) curves and $\mathrm{K}^{+}: \mathrm{Na}^{+}, \mathrm{Mg}^{2+}: \mathrm{Na}^{+}$, and $\mathrm{Ca}^{2+}: \mathrm{Na}^{+}$ratios. Also, lower levels of electrolyte leakage, malonaldehyde, $\mathrm{H}_{2} \mathrm{O}_{2}$, superoxide dismutase, peroxidase, and ascorbate peroxidase activities suggested that NO reduced the membrane injury and lipid peroxidation under salt treatment, while PL regime showed severe damage. In summary, our results suggest that NO has some beneficial effects on the maintenance of cell membrane stability, alleviation of oxidative damage and maintenance of ion homeostasis and plant photosythesis when bermudagrass is exposed to high salinity condition.
\end{abstract}

Salinity is an ever-present environmental factor that influences the growth and development of plant. Although it is an essential factor for botanical species, high salinity can disturb normal inner operations of plant and even lead to plant death (Hasegawa et al., 2000). Exposure to a high concentration of salt causes ion imbalance and hyperosmotic stress to plant cells, which could cause overproduction of reactive oxygen species (ROS) in many plant species (Koca et al., 2007; Lechno et al., 1997; Moradi and Ismail, 2007). It has been documented that the ROS can lead to a significant cell membrane damage manifesting in the form of increased malonaldehyde (MDA) content, increased electrolyte leakage (EL), and pronounced activity of antioxidases, such as superoxide dismutase (SOD), peroxidase (POD), and ascorbate peroxidase (APX) (Hu et al., 2012; Meloni et al., 2003). Also, high salinity can alter normal plant processes. Studies have revealed that it could cause the attenuation of metabolic activity (Zhao and Qin, 2004), photosynthesis dysfunction (Shu et al., 2012), and limited water and nutrient uptake by a plant (Romero-Aranda et al., 2001). Previous studies have confirmed that the overall area of

Received for publication 19 Apr. 2016. Accepted for publication 3 June 2016. This work was supported by the China National Science Foundation (NSFC) (grant nos. 31401915 and 31272194), China-Africa Center for Research and Education (grant no. SAJC201325), the Hubei Province National Science Foundation Sciences (grant no. ZRY1326), and the outstanding young talent program of CAS Key Laboratory of Plant Germplasm Enhancement and Specialty Agriculture (grant no. Y452341X01).

1'Corresponding author. E-mail: jfu@wbgcas.cn or chenliang1034@126.com. alkaline soil on the earth is $\approx 700$ million hectares (Xie et al., 2009). Therefore, it is imperative to find a way to protect and improve salt tolerance in plants, especially in countries where agriculture is crucially important but with large amount of alkaline soil (Abdelly et al., 2008).

Nitric oxide has been proved to be a vital regulator of various biological processes (Laspina et al., 2005). It can be produced in plants with the assistance of nitric oxide synthase (NOS) and nitrate reductase (NR), which was reported in many species, such as Arabidopsis thaliana and Glycine max (Guo et al., 2003; Wildt et al., 1997). It is commonly observed that NO can serve as an antioxidant in plant cells. Low concentration of NO can interact with ROS to reduce its accumulation, which would in turn block the ROS-mediated oxidative damage (Ruan et al., 2002). Nitric oxide has also been documented to act as signaling molecule to affect the activities of enzymes that alter ROS level (Neill et al., 2008). Nitric oxide involves in many growth and development processes of plant. It was reported that exogenous NO could promote seed germination, improve the activity of photosynthesis, and regulate maturation and senescence of plant (Beligni and Lamattina, 2000; Chen et al., 2013; Ya'acov et al., 1998). It was also observed that NO was able to mediate plant responses to various abiotic stresses. Uchida et al. (2002) reported that NO has a positive effect on rice (Oryza sativa L.) under heat and salt stresses. Laspina et al. (2005) observed that NO was efficient to protect sunflower (Helianthus annuus L.) plant against Cd-induced oxidative stress. Besides, $\mathrm{NO}$ was also able to alleviate the damage effects of ultraviolet-B 
radiation (Santa-Cruz et al., 2010). Furthermore, NO was recorded to be involved in reducing the salt stress of wheat [Triticum aestivum L. (Ruan et al., 2002)]. However, the role of $\mathrm{NO}$ in bermudagrass response to salt stress is unknown.

As an essential and sensitive physiological process in plants, photosynthesis can serve as an indicator to reflect the extent of damage in plants (Silva et al., 2010). OJIP transient can be used to translate original chlorophyll $a(\mathrm{Chl} a)$, measure the photosynthetic processes efficiency and kinetics that involving in photosystem II (PSII), which is based on the theory of energy fluxes in bio-membranes (Tóth et al., 2007; Tsimilli-Michael and Strasser, 2008). It was reported that high salinity could directly disturb photosynthetic electron transport chain, constraining the photosynthetic rate and photochemical efficiency of plant (Brugnoli and Lauteri, 1991; Hoffman et al., 1980; Meloni et al., 2003). However, the information concerning the effect of NO on plant's photosynthetical system under salt stress is limited.

Bermudagrass, a typical warm-season turfgrass with preeminent growth rate, can be used as a forage grass and has the potential to improve saline and alkaline soils (Fuller et al., 1982; Hameed and Ashraf, 2008; Li and Qu, 2004). However, high salinity limits its utilization (Langdale and Thomas, 1971). Therefore, it is urgent to improve its salt stress tolerance. We here investigated whether and how NO is involved in protecting bermudagrass against salt stress and aimed to provide more information about bermudagrass for soil improvement use.

\section{Materials and Methods}

Plant material and growth conditions. Bermudagrass employed in this study came from wild fields of Xiaojiang City, Zhejiang Province, China. Stolons were well distributed in plastic pots ( $9.0 \mathrm{~cm}$ deep, $7.5 \mathrm{~cm}$ diameter) filled with a matrix ( 1 brown coal soil: 1 sand) in Nov. 2015. At the bottom of each pot, two drainage holes of $\approx 5 \mathrm{~mm}$ diameter were used to drain excessive water and ensure soil aeration. Plastic plates were put at the bottom of each pot to collect the extra water. All pots were kept in the greenhouse for 5 weeks with the condition of a daily temperature of average 25 day $/ 20{ }^{\circ} \mathrm{C}$ night and $50 \%$ relative humidity. During the period, plants were irrigated and fertilized every $2 \mathrm{~d}$ with half-strength Hoagland's solution until the solution drained out from the holes at the bottom of the pots (Hoagland and Arnon, 1950).

Treatments. When the third leaf was fully expanded, the pots with established grass was transferred into growth chamber (LSC-339CF; Xingxing Group Co., Zhejiang, China), which was used to provide a constant condition. The chamber worked with a 12-h photoperiod and the light intensity on a horizontal plane above the canopy was averaged $240 \mu \mathrm{mol} \cdot \mathrm{m}^{-2} \cdot \mathrm{s}^{-1}$ photosynthetically active radiation $(P A R)$. Also, $30{ }^{\circ} \mathrm{C}$ and $60 \%$ relative humidity were set to culture plant. A $100 \mu \mathrm{M}$ sodium nitroprusside served as the NO donor and $200 \mu \mathrm{M}$ PTIO along with $200 \mu \mathrm{M} \mathrm{L-NAME}$ as the NO scavenger and NO production inhibitor (Xu et al., 2010a, 2010b), which were purchased from Sigma-Aldrich (Shanghai, China). The experiment consisted of six regimes and a split-plot design was maintained: 1) double-distilled water, 2) double-distilled water containing SNP, 3) double-distilled water containing PTIO along with L-NAME, 4) $400 \mathrm{~mm} \mathrm{NaCl}$ solution, 5) $400 \mathrm{~mm}$ $\mathrm{NaCl}$ solution containing SNP, and 6) $400 \mathrm{~mm} \mathrm{NaCl}$ solution containing PTIO along with L-NAME. For the three water regimes (treated with double-distilled water), $100 \mathrm{~mL}$ treatment solution was watered in specific pots and $50 \mathrm{~mL}$ solution were sprayed on the aerial parts of the plant. For the three salt regimes (treated with $400 \mathrm{~mm} \mathrm{NaCl}$ ), $100 \mathrm{~mL}$ mixed solution was watered in pots and $50 \mathrm{~mL}$ NO-related solution (without $\mathrm{NaCl}$ ) was sprayed on the aerial parts of bermudagrass. All the treatment were applied every $2 \mathrm{~d}$ for $4 \mathrm{~d}$. Fully expanded leaves in each pot were harvested and put into liquid nitrogen after $4 \mathrm{~d}$, then stored at $-80^{\circ} \mathrm{C}$ in a refrigerator for physiological analysis.

Measurements. Relative water content (RWC) and leaf chlorophyll content $(\mathrm{Chl})$ were measured to determine the damage extent of bermudagrass. Fresh and fully expanded leaves of all the regimes were weighed just after harvesting from the plant after $4 \mathrm{~d}$ and the weight recorded as the fresh weight (FW). The leaves were then submerged in the water for $8 \mathrm{~h}$. The saturated weight (SW) was recorded. Calculation of dry weight (DW) according to the following equation (Barrs and Weatherley, 1962):

$$
\operatorname{RWC}(\%)=\frac{(\mathrm{FW}-\mathrm{DW})}{(\mathrm{SW}-\mathrm{DW})} \times 100 \%
$$

Measurement of leaf chlorophyll content was conducted according to the method outlined by Hiscox and Israelstam (1979). In brief, fresh leaves were harvested at $4 \mathrm{~d}$ and $\approx 0.1 \mathrm{~g}$ leaves were cut into pieces and washed, blotted, and dipped in $10 \mathrm{~mL}$ dimethyl sulfoxide for $72 \mathrm{~h}$. The absorption of samples at 645 and $663 \mathrm{~nm}$ was measured using a spectrophotometer (ultraviolet-2600; UNICO Instruments Co., Shanghai, China). Calculation of total chlorophyll content was according to the formula:

$$
\mathrm{Chl}-\operatorname{total}\left(\mathrm{mg} \cdot \mathrm{L}^{-1}\right)=20.2 \times \mathrm{OD} 645+8.02 \times \mathrm{OD} 663
$$

Electrolyte leakage was analyzed according to the method of $\mathrm{Hu}$ et al. (2012). In brief, fresh leaves were harvested at $4 \mathrm{~d}$ and $\approx 0.1 \mathrm{~g}$ of treated leaves were rinsed three times with distilled water and excised to $\approx 0.5$-cm-long segments, which were then placed into a $50-\mathrm{mL}$ centrifuge tube with $15 \mathrm{~mL}$ deionized water. The tubes were shaken at room temperature for $24 \mathrm{~h}$. Measurement of the conductivity of the initial solution $\left(C_{\mathrm{A}}\right)$ was done with a conductivity meter (3173; Jenco Instruments, San Diego, CA). After that, the test tubes were heated at $95^{\circ} \mathrm{C}$ for $30 \mathrm{~min}$ to cause complete disruption of the cell structure and release of all electrolytes. The conductivity of the boiled solution with killed tissues $\left(C_{\mathrm{B}}\right)$ was determined after the solution cooled to room temperature. The percentage of electrolyte leakage was obtained using the formula:

$$
\operatorname{EL}(\%)=\left(C_{\mathrm{A}} / C_{\mathrm{B}}\right) \times 100 \%
$$

To extract crude enzyme, $\approx 0.2 \mathrm{~g}$ leaves were ground to a fine powder in liquid nitrogen, which was then mixed with $4 \mathrm{~mL}$ of $150 \mathrm{~mm}$ sodium phosphate buffer $(\mathrm{pH} 7.0)$ that was precooled at $4{ }^{\circ} \mathrm{C}$ (Fan et al., 2014). The homogenate was transferred into a 15-mL centrifuge tube. After that, it was centrifuged for $25 \mathrm{~min}$ at $13,000 g_{n}$ at $4{ }^{\circ} \mathrm{C}$. The supernatant was collected for physiological assays, including the content of $\mathrm{H}_{2} \mathrm{O}_{2}$, malonaldehyde (MDA), and enzyme activities.

MDA content was measured by the thiobarbituric acid (TBA) method described by Fan et al. (2014). In brief, $1 \mathrm{~mL}$ of crude enzyme solution was mixed with $2 \mathrm{~mL}$ MDA reaction buffer that included $20 \%(\mathrm{v} / \mathrm{v})$ trichloroacetic acid and $0.5 \%(\mathrm{v} / \mathrm{v}) \mathrm{TBA}$. 
The solution was then boiled at $95{ }^{\circ} \mathrm{C}$ for $30 \mathrm{~min}$, cooled to room temperature, and centrifuged for $10 \mathrm{~min}$ at $12,000 \mathrm{~g}_{\mathrm{n}}$ at $20{ }^{\circ} \mathrm{C}$. The absorbance of the supernatant at 532 and $600 \mathrm{~nm}$ was measured, respectively. The MDA content was obtained using the following formula: $\operatorname{MDA}\left(\mathrm{mol} \cdot \mathrm{g}^{-1} \mathrm{FW}\right)=$ $[(\mathrm{OD} 532-\mathrm{OD} 600) \times \mathrm{L}] /(1 \times \epsilon \times \mathrm{FW})$, where $\mathrm{L}$ is the volume of the extract solution, 1 is the thickness of the cuvettes, $\epsilon$ is the extinction coefficient of $155 \mathrm{~mm}^{-1} \cdot \mathrm{cm}^{-1}$, and FW is the fresh weight of collected leaves.

The content of $\mathrm{H}_{2} \mathrm{O}_{2}$ was calculated according to the method of Nanjing Jiancheng Bioengineering Institute (NJBI, Nanjing, China) determination kit. One hundred microliters of crude enzyme solution was used.

Estimation of the SOD activity was based on the method of Giannopolitis and Ries (1977) but with some modifications. The reaction solution consisted of $3 \mu \mathrm{M}$ ethylenediaminetetraacetic acid, $60 \mu \mathrm{M}$ riboflavin, $195 \mathrm{~mm}$ methionine, $50 \mathrm{~mm}$ sodium phosphate buffer ( $\mathrm{pH} 7.8), 1.125 \mathrm{~mm}$ nitro blue tetrazolium (NBT). One hundred microliters of crude enzyme solution was mixed with $2.9 \mathrm{~mL}$ reaction solution, while $3 \mathrm{~mL}$ reaction solution served as the control. After that, the homogenized mixture was illuminated under a 4000-lx fluorescent lamp for $30 \mathrm{~min}$ and the absorbance documented at $560 \mathrm{~nm}$. One unit of enzyme activity was defined as the amount of enzyme required to inhibit the NBT reduction by $50 \%$. Detection of the POD activity was according to the method Chance and Maehly (1955) described. Fifty microliters of crude enzyme solution was added to the reaction solution, in a total volume of $2.95 \mathrm{~mL}$, containing $1.85 \mathrm{~mL} 100 \mathrm{~mm}$ sodium acetate-acetic acid buffer $(\mathrm{pH} 5.0)$, $1 \mathrm{~mL} 0.25 \%$ guaiacol, and $0.1 \mathrm{~mL} 0.75 \% \mathrm{H}_{2} \mathrm{O}_{2}$. Absorbance at $460 \mathrm{~nm}$ was documented at 1-min intervals for $3 \mathrm{~min}$. A unit of POD activity represented the absorbance change of 1 unit per minute. A reagent kit purchased from NJBI, which was employed to detect the APX activity.

Original Chl $a$ fluorescence transient can be used to evaluate the photosynthesis of plant (Tóth et al., 2007; Tsimilli-Michael and Strasser, 2008). In the study, the third fully expanded leaves were collected at $4 \mathrm{~d}$ after treatment (DAT) and all the measurements were repeated at least three times by using pulse-amplitude modulation (PAM) fluorimeter (PAM 2500; Heinz Walz, Effeltrich, Germany) with high time resolution $(10 \mu \mathrm{s})$. Leaves were treated with a dark adaptation for $30 \mathrm{~min}$ to ensure closure of all PSII reaction centers and to obtain a true fluorescence intensity (Chen et al., 2013). A $3000-\mu \mathrm{mol} \cdot \mathrm{m}^{-2} \cdot \mathrm{s}^{-1}$ red light was generated by the fluorimeter (PAM 2500) through an array of light-emitting diodes triggered the OJIP transients.

At the end of the treatment, the leaves of bermudagrass were harvested separately and washed thoroughly with distilled water. The samples were put into an oven at $105{ }^{\circ} \mathrm{C}$ for $30 \mathrm{~min}$ to deactivate the enzymes before being oven-dried at $80{ }^{\circ} \mathrm{C}$ for $48 \mathrm{~h}$. After that, the leaves were ground into a fine powder and the samples $(100 \mathrm{mg})$ were digested in a mixture of concentrated $\mathrm{HClO}_{4}$ and $\mathrm{HNO}_{3}(1: 4, \mathrm{v} / \mathrm{v})$. Each sample was diluted to $50 \mathrm{~mL}$ using double deionized water. The contents of $\mathrm{K}$, $\mathrm{Na}$, $\mathrm{Ca}$, and $\mathrm{Mg}$ accumulation were measured using inductively coupled plasma mass spectroscopy (Thermo Fisher Scientific, Waltham, MA). Each experiment was replicated three times. The results for all the elements measured $(\mathrm{K}, \mathrm{Mg}$, $\mathrm{Ca}$, and $\mathrm{Na}$ ) were calculated by expressing the atomic number of a particular element in a given plant as a percentage of the total atomic number in the plant (Zhao et al., 2004).

At least three biological replicates were used in experiment for all the experiments, and values were given as mean \pm SD. All the data were evaluated by Duncan's multiple range tests using one-way analysis of variance, means differences were separated at $P<0.05$ using the statistical package SPSS (version 16.0; IBM, Armonk, NY) and Excel (2010 for Windows; Microsoft, Redmond, WA).

\section{Results}

RELATIVE WATER CONTENT AND CHLOROPHYLL CONTENT. The RWC and the chlorophyll content were regarded as indicators to evaluate the extent of the damage in the stress-treated plant. At DAT, salt stress significantly reduced the RWC (Fig. 1A). The salt treatment reduced $\mathrm{RWC}$ by $10.7 \%$ relative to the control. PTIO along with L-NAME caused a pronounced
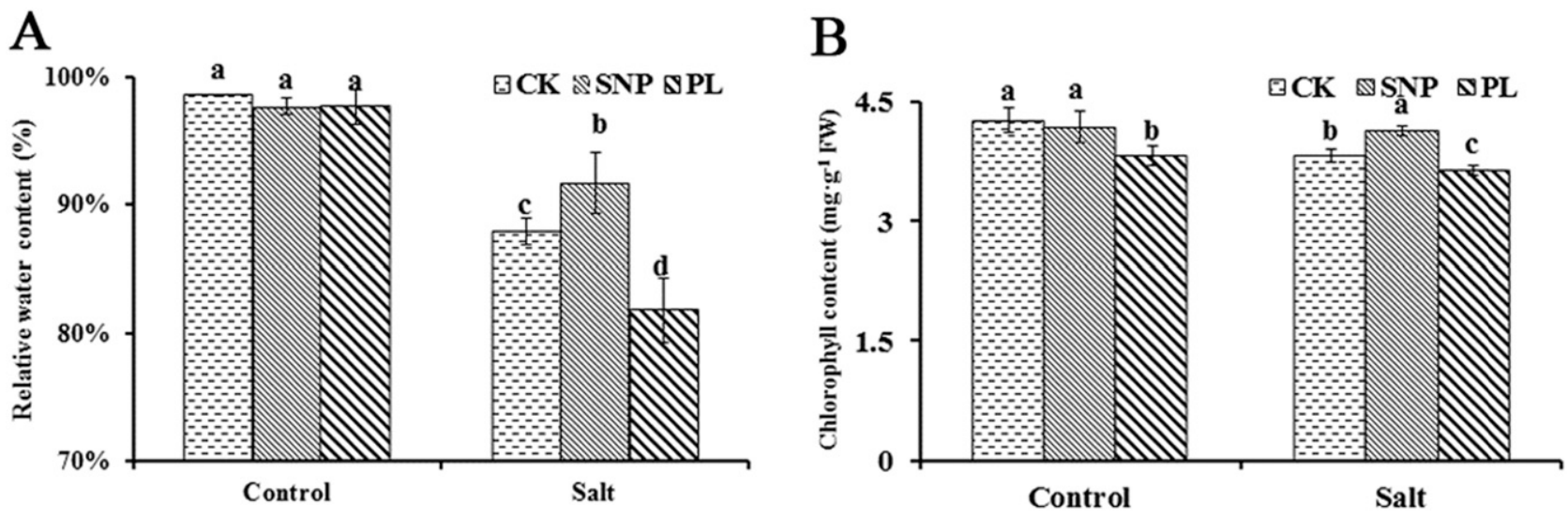

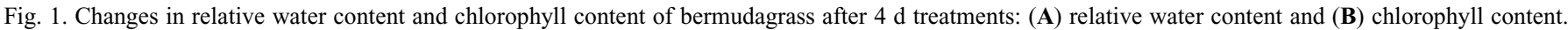
Bermudagrass used in this study has grown in the greenhouse for 5 weeks and then the pots with established grass was transferred into growth chamber for $4 \mathrm{~d}$ with a 12-h photoperiod and the light intensity on a horizontal plane above the canopy averaged $240 \mu \mathrm{mol} \cdot \mathrm{m}^{-2} \cdot \mathrm{s}^{-1} \mathrm{photosynthetically} \mathrm{active} \mathrm{radiation.} \mathrm{The} \mathrm{experiment}$ included three biological replicates of each treatment. The control (CK) was plants treated with double-distilled water. The salt regime included 400-mm salinity solution. SNP refers to $100 \mu \mathrm{M}$ sodium nitroprusside. PL was $200 \mu \mathrm{M}$ 2-phenyl-4,4,5,5-tetramentylimidazoline-1-oxyl-3-xide and 200 $\mu \mathrm{M}$ NG-nitro-L-arginine methyl ester applied together. Calculation of the mean values and the SD used data from the three biological replicates. The bars show sD, while the different letters indicate the significant statistical differences at $P<0.05$ among the treatments according to Duncan's multiple range tests. 

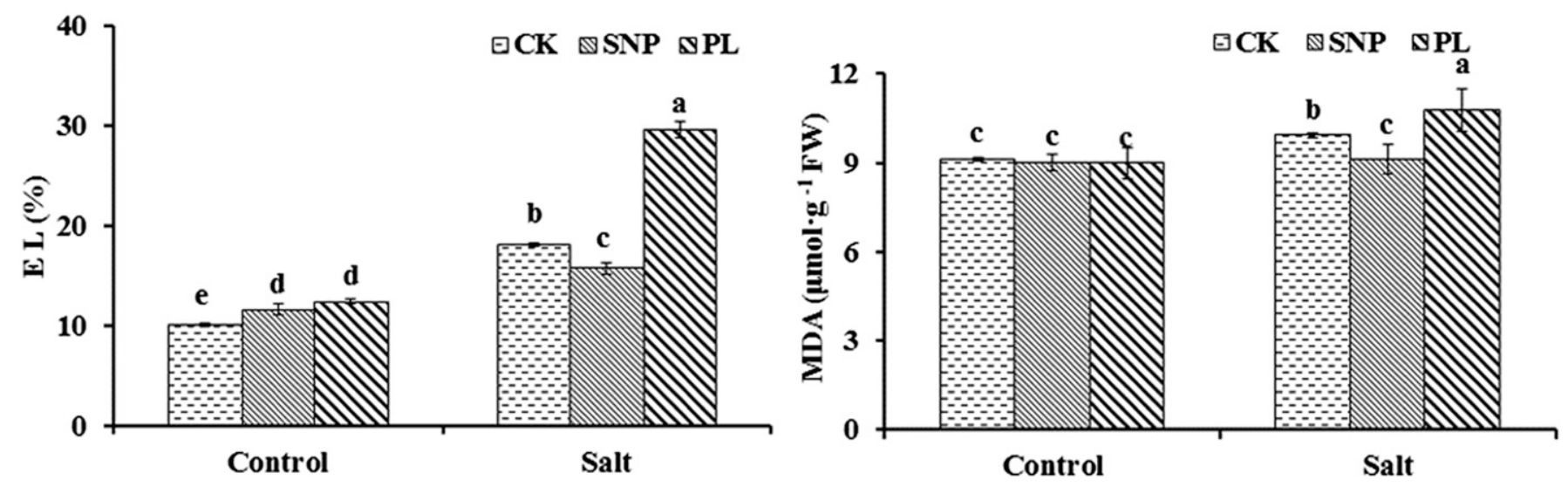

Fig. 2. Changes of cell membrane stability and lipid peroxidation in the leaves of bermudagrass after $4 \mathrm{~d}$ treatments: (A) electrolyte leakage (EL) and (B) malonaldehyde (MDA) content. Bermudagrass used in this study has grown in the greenhouse for 5 weeks and then the pots with established grass was transferred into growth chamber for $4 \mathrm{~d}$ with a 12 -h photoperiod and the light intensity on a horizontal plane above the canopy averaged $240 \mu \mathrm{mol} \cdot \mathrm{m}^{-2} \cdot \mathrm{s}^{-1} \mathrm{photosynthetically}$ active radiation. The experiment included three biological replicates of each treatment. The control (CK) was plants treated with double-distilled water. The salt regime included 400-mm salinity solution. SNP refers to $100 \mu \mathrm{m}$ sodium nitroprusside. PL was $200 \mu \mathrm{m}$ 2-phenyl-4,4,5,5-tetramentylimidazoline-1-oxyl-3-xide and $200 \mu \mathrm{M}$ NG-nitro-L-arginine methyl ester applied together. Calculation of the mean values and the sDS used data from the three biological replicates. The bars show SD, while the different letters indicate the significant statistical differences at $P<0.05$ among the treatments according to Duncan's multiple range tests.

decrease $(15.9 \%)$ in RWC. However, SNP had a positive effect on bermudagrass under salt treatment since only $6.0 \%$ decline of RWC was observed. Total chlorophyll content of the control (CK) regime was $8.3 \%$ lower than that of SNP treatment (Fig. 1B) while the chlorophyll content of PTIO along with L-NAME regime was $4.7 \%$ lower than that of the control under nonsalt stress conditions.

Membrane inJury and LiPID PERoXidation. MDA and EL can be used as efficient indicators of lipid peroxidation, which further reflects the extent of damage of cell membrane (Södergren et al., 2001; Whitlow et al., 1992). Generally, higher cell membrane stability indicates excellent tolerance to abiotic stress. In this study, the EL value of SNP-treated plant under salt stress was $2.3 \%$ lower than that of the $\mathrm{CK}$ under salt stress. On the contrary, when treated with NO scavenger and inhibitor (PTIO plus L-NAME), the bermudagrass showed $11.5 \%$ higher EL than that of the CK (Fig. 2A). Exogenous NO effectively protected the membrane integrity given that the similar results were obtained for the MDA content (Fig. 2B). The MDA content rose by $8.9 \%$ under salt stress compared with the control. The results also showed that SNP could decrease the harmful effects of salt stress on bermudagrass, considering only $1.2 \%$ increased MDA content compared with that of the control. However, the MDA values were increased by $20.1 \%$ by treatment of PTIO along with L-NAME as compared with control level.

To further reveal the impact of NO on ROS in plant under salt stress, the $\mathrm{H}_{2} \mathrm{O}_{2}$ content was measured. Results showed that the $\mathrm{H}_{2} \mathrm{O}_{2}$ content increased by $131.7 \%$ under salt stress while the PTIO plus L-NAME regime showed $13.0 \%\left(6.93 \mathrm{~mol} \cdot \mathrm{g}^{-1}\right.$ fresh weight) higher as compared with CK under salt stress. By contrast, when compared with the $\mathrm{CK}$ under salt stress, there was a lower value of $\mathrm{H}_{2} \mathrm{O}_{2}$ content showed in SNP regime (Fig. 3).

Antioxidative EnZYMes. The effect of NO on antioxidant enzymes was analyzed based on SOD, POD, and APX. These three enzymes activity showed a steep rise under salt treatments when compared with control (Fig. 4), indicating that the

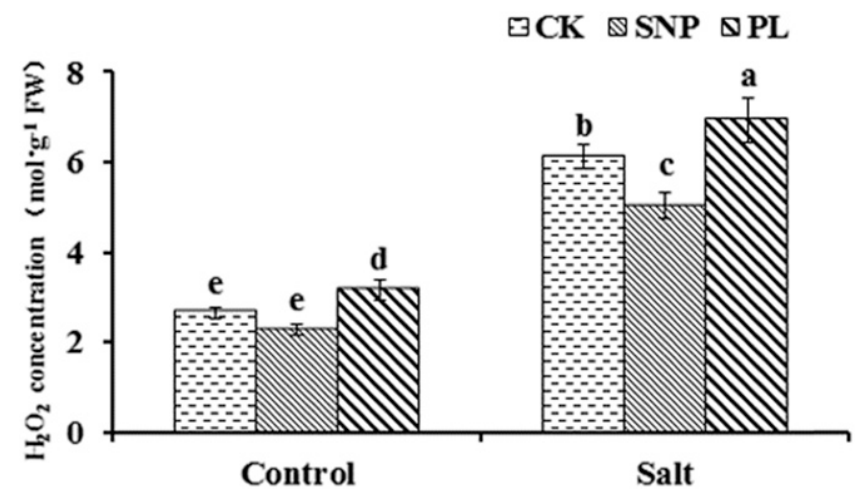

Fig. 3. Changes of $\mathrm{H}_{2} \mathrm{O}_{2}$ content in the leaves of bermudagrass after $4 \mathrm{~d}$ of different treatments. Bermudagrass used in this study has grown in the greenhouse for 5 weeks and then the pots with established grass was transferred into growth chamber for $4 \mathrm{~d}$ with a 12-h photoperiod and the light intensity on a horizontal plane above the canopy averaged $240 \mu \mathrm{mol} \cdot \mathrm{m}^{-2} \cdot \mathrm{s}^{-1}$ photosynthetically active radiation. The experiment included three biological replicates. The control $(\mathrm{CK})$ was plants treated with double-distilled water. The salt regime included 400-mm salinity solution. SNP refers to $100 \mu \mathrm{M}$ sodium nitroprusside. PL was $200 \mu \mathrm{M}$ 2-phenyl-4,4,5,5-tetramentylimidazoline-1-oxyl-3-xide and $200 \mu \mathrm{M}$ NG-nitro-L-arginine methyl ester applied together. Calculation of the mean values and the SD used data from the three biological replicates. The bars show SD, while the different letters indicate the significant statistical differences at $P<0.05$ among the treatments according to Duncan's multiple range tests.

defense system was activated when bermudagrass encountered salt stress. The SNP effectively alleviated the injury; the activity of the three enzymes decreased by $18.5 \%, 8.8 \%$, and $10.7 \%$ as compared with their performance in plant subjected to treatment with a salt solution, respectively. However, the NO scavenger and inhibitor regime showed the highest level of enzymes' activity in all the three antioxidant enzymes, and resulted in $18.6 \%, 17.0 \%$, and $16.8 \%$ higher level at 4 DAT compared with the control, respectively.

Рнотоsynthesis system. OJIP fluorescence transient was analyzed to examine the impact of NO on photosynthesis 
A

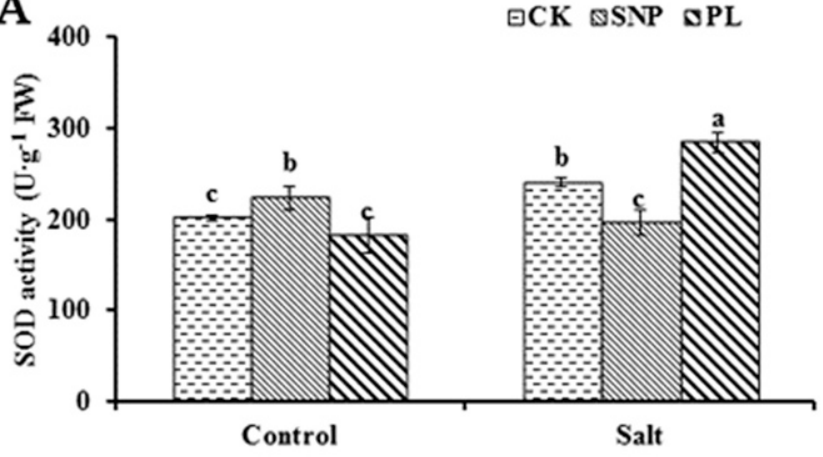

B

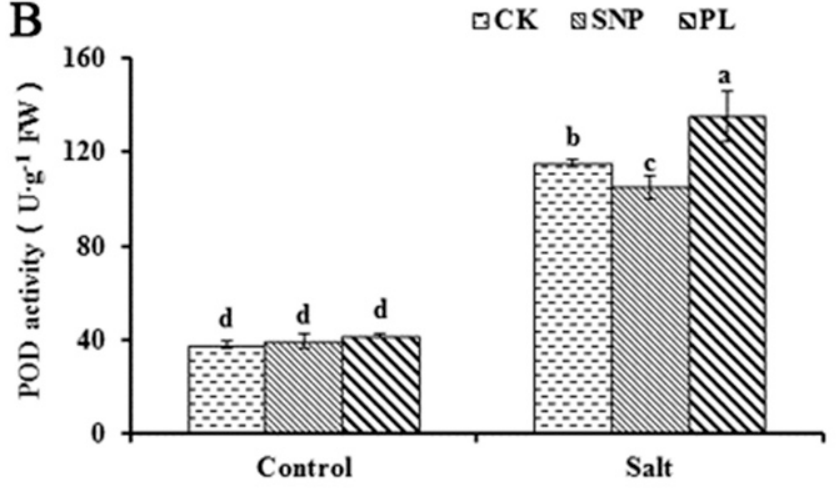

C

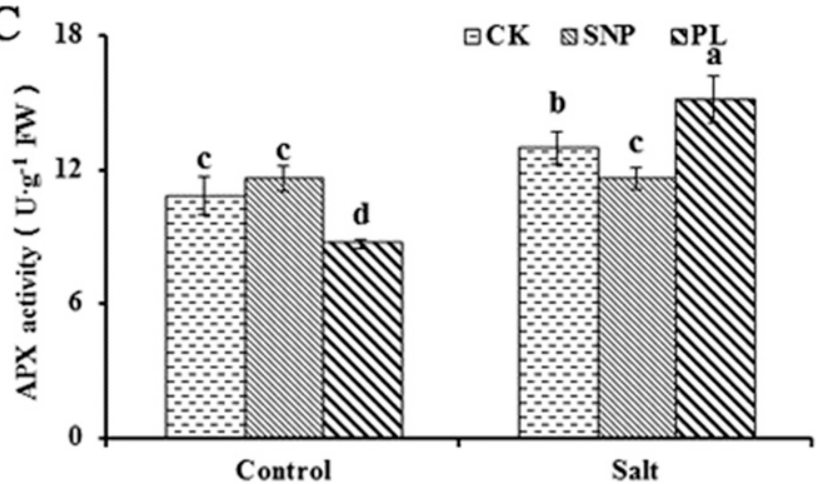

Fig. 4. Changes in the activity of antioxidant enzymes present in the leaves of bermudagrass after $4 \mathrm{~d}$ of different treatments: $(\mathbf{A})$ the activity of superoxide dismutase (SOD), (B) peroxidase (POD), and (C) acorbate peroxidase (APX). Bermudagrass used in this study has grown in the greenhouse for 5 weeks and then the pots with established grass was transferred into growth chamber for $4 \mathrm{~d}$ with a 12-h photoperiod and the light intensity on a horizontal plane above the canopy averaged $240 \mu \mathrm{mol} \cdot \mathrm{m}^{-2} \cdot \mathrm{s}^{-1}$ photosynthetically active radiation. The experiment included three biological replicates. The control (CK) was plants treated with double-distilled water. The salt regime included 400-mM salinity solution. SNP refers to $100 \mu \mathrm{M}$ sodium nitroprusside. PL was $200 \mu \mathrm{M}$ 2-phenyl-4,4,5,5-tetramentylimidazoline-1-oxyl-3-xide and $200 \mu \mathrm{M}$ NG-nitro$\mathrm{L}$-arginine methyl ester applied together. Calculation of the mean values and the SD used data from the three biological replicates. The bars show SD, while the different letters indicate the significant statistical differences at $P<0.05$ among the treatments according to Duncan's multiple range tests.

system. In our study, the OJIP curves dropped for all of the salttreated regimes (Fig. 5), while there was no significant difference in plant treated with control and PTIO plus L-NAME. On the other hand, SNP dramatically alleviated the damage effects indicated by higher OJIP curves (Fig. 5B). These results confirm that NO had a positive impact on the photosynthesis system of bermudagrass' leaves.
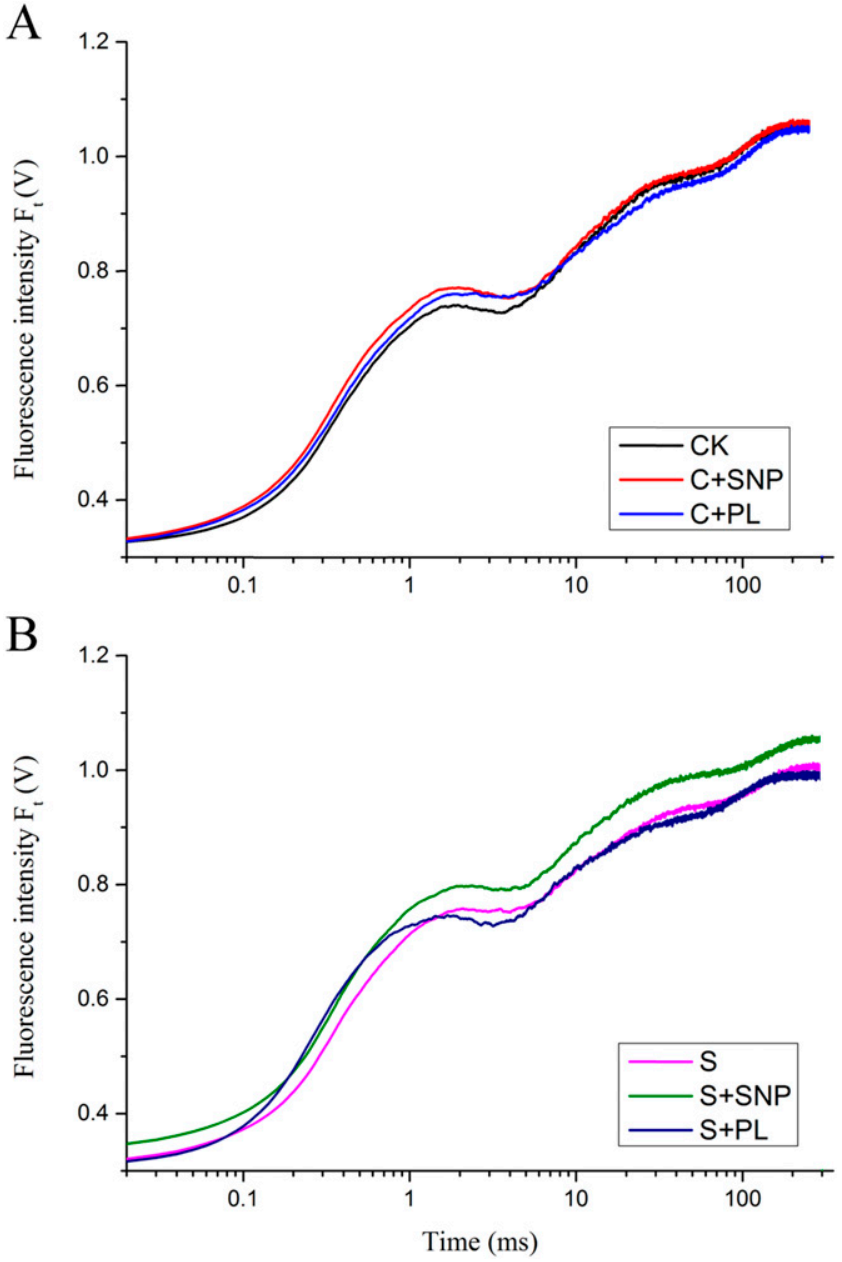

Fig. 5. Changes of chlorophyll fluorescence transients (OJIP curve) in the leaves of bermudagrass after $4 \mathrm{~d}$ treatments. Bermudagrass used in this study has grown in the greenhouse for 5 weeks and then the pots with established grass was transferred into growth chamber for $4 \mathrm{~d}$ with a 12 -h photoperiod and the light intensity on a horizontal plane above the canopy was averaged $240 \mu \mathrm{mol} \cdot \mathrm{m}^{-2} \cdot \mathrm{s}^{-1}$ photosynthetically active radiation. The experiment included three biological replicates. The control (CK) was plants treated with double-distilled water. The salt regime included 400-mM salinity solution. SNP refers to $100 \mu \mathrm{m}$ sodium nitroprusside. PL was $200 \mu \mathrm{M}$ 2-phenyl-4,4,5,5-tetramentylimidazoline-1-oxyl3-xide and $200 \mu \mathrm{M}$ NG-nitro-L-arginine methyl ester applied together.

Changes in Elements' Ratios IN THE Bermudagrass UNDER SALT STRESS. Ionic balance plays a major role in plants' adaption to salt stress (Zhao et al., 2004). In this study, we calculated the ratios of different elements when grass was under to salt stress. The results indicated that the content of $\mathrm{K}, \mathrm{Mg}$, and $\mathrm{Ca}$ decreased by $41.5 \%, 47.2 \%$, and $35.5 \%$, respectively, on treating the plant with $400 \mathrm{~mm}$ salt stress. However, the $\mathrm{Na}$ content increased by $55.2 \%$. SNP effectively alleviated the adverse effect; the $\mathrm{K}, \mathrm{Mg}$, and $\mathrm{Ca}$ contents were $28.2 \%, 22.1 \%$, and $34.7 \%$, respectively, higher than in plant only treated with a salt solution and the $\mathrm{Na}$ content was $12.4 \%$ lower in SNP regime. On the contrary, the PTIO plus L-NAME enhanced the damage of salt stress (Fig. 6). To further understand the effects of NO on ionic balance, we examined the $\mathrm{K}^{+}: \mathrm{Na}^{+}, \mathrm{Mg}^{2+}: \mathrm{Na}^{+}$, and $\mathrm{Ca}^{2+}: \mathrm{Na}^{+}$ratios. When treated with salt stress, the ratios of all the three elements decreased by $62.3 \%, 66.1 \%$, and $70.5 \%$, respectively, when compared with the control. In this study, exogenous SNP increased all the three ratios under salt 
A

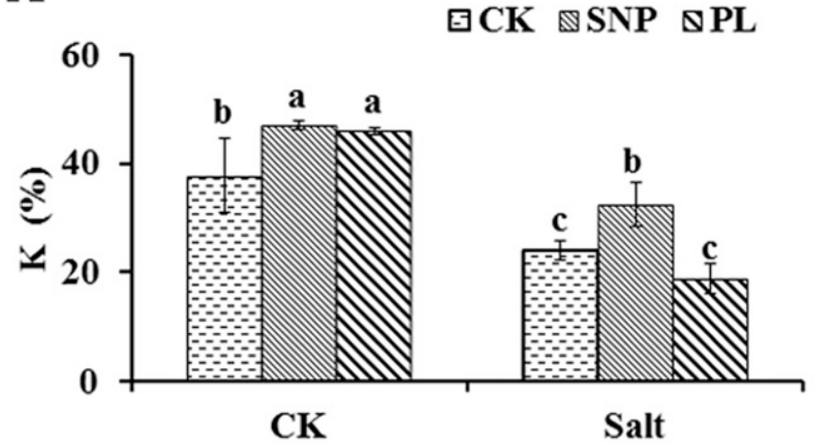

C

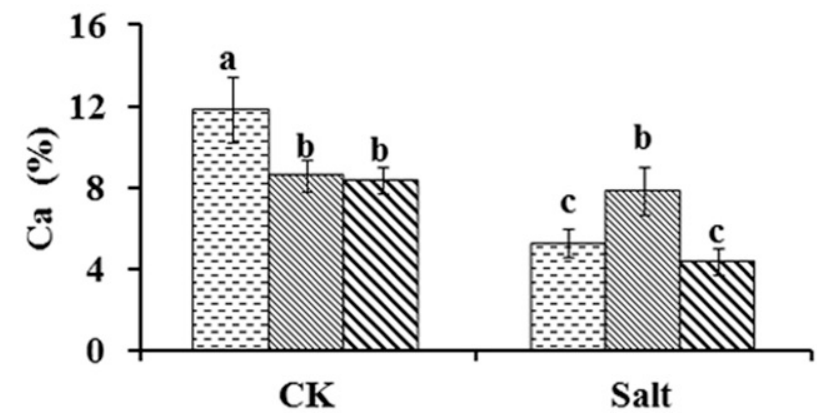

B

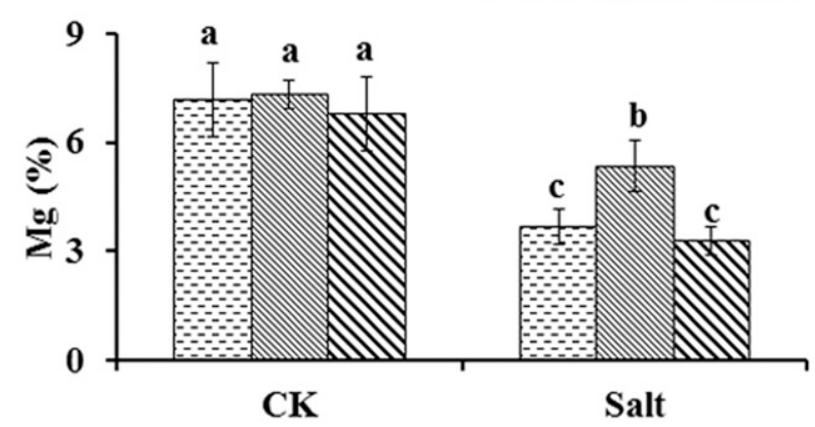

D

$\Xi C K \mathbb{S N P} \otimes P L$

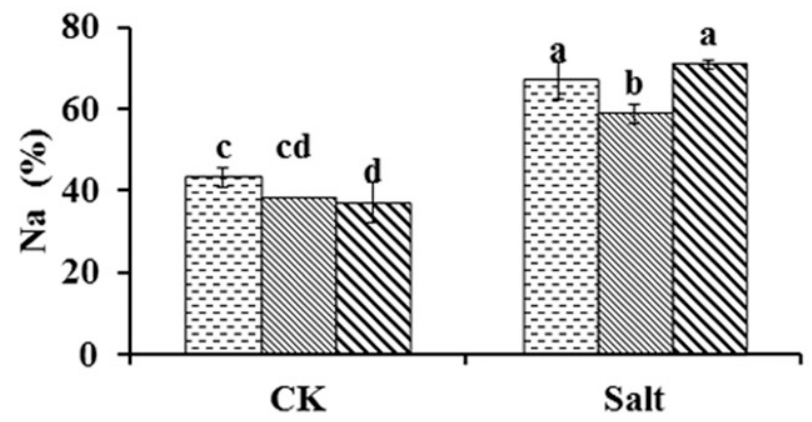

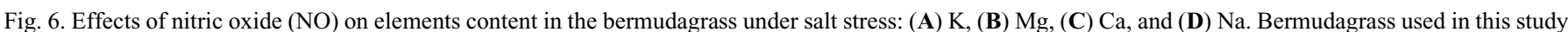
has grown in the greenhouse for 5 weeks and then the pots with established grass was transferred into growth chamber for $4 \mathrm{~d}$ with a 12 -h photoperiod and the light intensity on a horizontal plane above the canopy averaged $240 \mu \mathrm{mol} \cdot \mathrm{m}^{-2} \cdot \mathrm{s}^{-1}$ photosynthetically active radiation. The experiment included three biological replicates. The control (CK) was plants treated with double-distilled water. The salt regime included 400 -mm salinity solution. SNP refers to $100 \mu \mathrm{M}$ sodium nitroprusside. PL was $200 \mu \mathrm{m} 2$-phenyl-4,4,5,5-tetramentylimidazoline-1-oxyl-3-xide and $200 \mu \mathrm{m}$ NG-nitro-L-arginine methyl ester applied together. Calculation of the mean values and the SD used data from the three biological replicates. The bars show SD, while the different letters indicate the significant statistical differences at $P<0.05$ among the treatments according to Duncan's multiple range tests.

treatment; the $\mathrm{K}^{+}: \mathrm{Na}^{+}$ratio reached its maximum $(31.7 \%$ higher than of plant treated with a salt solution only), the $\mathrm{Mg}^{2+}: \mathrm{Na}^{+}$ ratio increased by $27.8 \%$, and the $\mathrm{Ca}^{2+}: \mathrm{Na}^{+}$ratio also showed a $54.7 \%$ increase. However, on the application of PTIO along with L-NAME to bermudagrass, $\mathrm{K}^{+}: \mathrm{Na}^{+}, \mathrm{Mg}^{2+}: \mathrm{Na}^{+}$, and $\mathrm{Ca}^{2+}: \mathrm{Na}^{+}$ratio decreased by $19.5 \%, 24.6 \%$, and $30.2 \%$, respectively, when compared with the turfgrass treated with high salinity only (Fig. 7).

\section{Discussion}

There are $\approx 36.3$ million hectares of salinized land in China, and most of it lies in northern China (Zhang and Shijie, 2001). Harnessing and preventing the salinization of soil are essential processes for agricultural production, environmental health, and economic welfare. Bermudagrass has the potential to improve salinized land because of its pre-eminent growth rate and good salt tolerance under low salinity condition (Fuller et al., 1982; Li and Qu, 2004). However, high salinity can still cause a severe damage to bermudagrass, which limits the use of bermudagrass on soil improvement. Thus, it is imperative to find a way to enhance its salt tolerance for improving salinized land use. In this study, the salt treatment caused significant damage to bermudagrass, suggesting that its tolerance declined under high salinity. However, exogenously applied NO alleviated the deleterious effects, while the NO scavenger plus NO production inhibitor aggravated the damage.

The estimation of the RWC and total chlorophyll content enabled evaluation of plant damage in the leaves of bermudagrass
(Fig. 1). High salinity led to a significant decrease of RWC, which was partially restored by the SNP application, suggesting that NO can help bermudagrass under salt stress to maintain water uptake and avoid leaf water deficits. On the contrary, without NO, the stability of the cell experienced severe damage as indicated by lower relative water content. These results resonate with those of Fan et al. (2015), who reported that NO plays a significant role in alleviating water loss and cell membrane damage, hence enhancing the tolerance of bermudagrass to cold stress. Similar results were observed for the total Chl content (Fig. 1B). High salinity caused a decrease of Chl content, and NO scavenger along with NO production inhibitor aggravated this effect. However, $100 \mu \mathrm{M}$ SNP reversed the damage. Previous researches revealed that $\mathrm{Chl}$ content decreased during plant senescence, and a further study suggested that salt stress would promote the senescence process of the plant cells (Dhindsa et al., 1981; Lutts et al., 1996). Ya'acov et al. (1998) proved that NO can delay the senescence of plant. Thus, the maintenance of the $\mathrm{Chl}$ content was probably due to the influence of $\mathrm{NO}$ in delaying senescence. Also, Chl content strongly relates to photosynthesis. In our study, higher OJIP curves were observed in SNP-treated plant, which suggested the involvement of NO in photosynthesis system under salt stress and its ability to alleviate the damage caused by salt stress (Fig. 5). Our results closely resonate with those of Fan et al. (2015), who reported that NO participates in electron transfer of PSII and the photosynthetic reaction is sensitive to NO treatment in bermudagrass. 


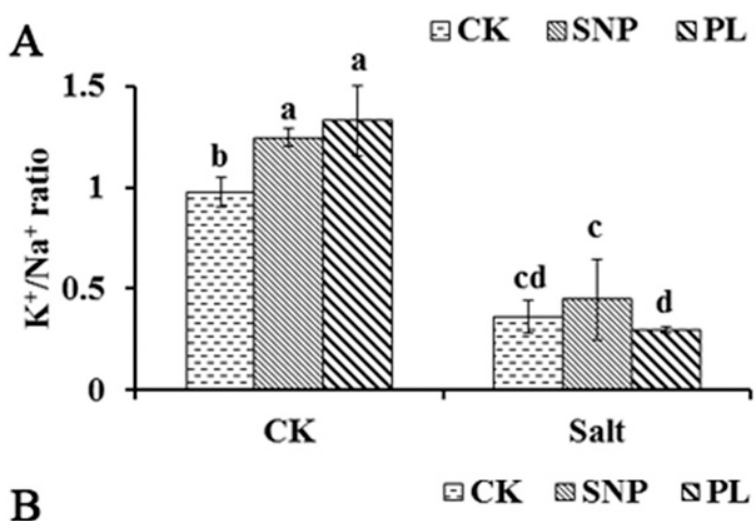

B

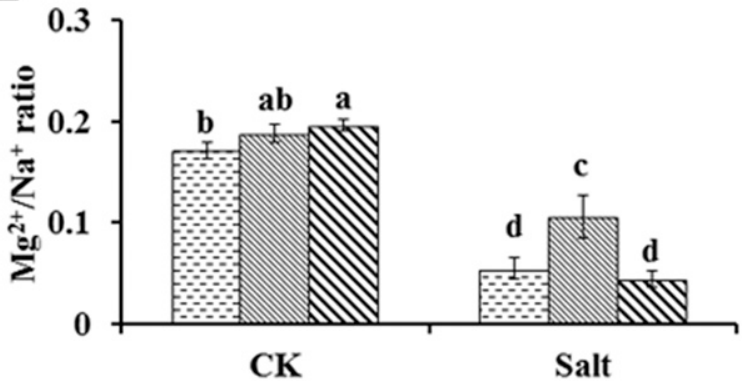

C

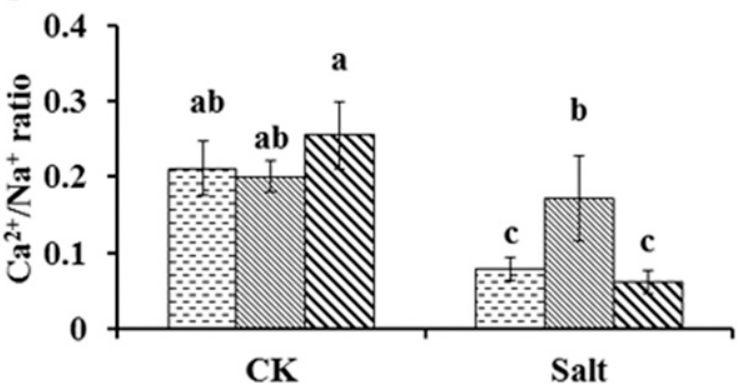

Fig. 7. Effects of nitric oxide (NO) on elements ratio in the bermudagrass under salt stress: (A) $\mathrm{K}^{+}: \mathrm{Na}^{+}$ratio, (B) $\mathrm{Mg}^{2+}: \mathrm{Na}^{+}$ratio, and (C) $\mathrm{Ca}^{2+}: \mathrm{Na}^{+}$ratio. Bermudagrass used in this study has grown in the greenhouse for 5 weeks and then the pots with established grass was transferred into growth chamber for $4 \mathrm{~d}$ with a 12-h photoperiod and the light intensity on a horizontal plane above the canopy averaged $240 \mu \mathrm{mol} \cdot \mathrm{m}^{-2} \cdot \mathrm{s}^{-1}$ photosynthetically active radiation. The experiment included three biological replicates. The control (CK) was plants treated with double-distilled water. The salt regime included 400-mm salinity solution. SNP refers to $100 \mu \mathrm{M}$ sodium nitroprusside. PL was $200 \mu \mathrm{M}$ 2-phenyl-4,4,5,5-tetramentylimidazoline-1-oxyl-3-xide and $200 \mu \mathrm{M}$ NG-nitroL-arginine methyl ester applied together. Calculation of the mean values and the SD used data from the three biological replicates. The bars show SD, while the different letters indicate the significant statistical differences at $P<0.05$ among the treatments according to Duncan's multiple range tests.

The stability of the cell membrane stability has a negative correlation to the extent of cellular damages (Premachandra et al., 1992). In this study, salt stress significantly increased MDA content and EL (Fig. 2). The PTIO plus L-NAME treatment caused more dramatic changes, while the plant treated with SNP showed a lower level of MDA and EL as compared with controls. These results suggested that NO could protect the cell membrane against the damage exerted by salt stress, which resonates with the variations of RWC and $\mathrm{Chl}$ content.

Reactive oxygen species, such as hydrogen peroxide, can lead to oxidative damage in plant. Superoxide dismutase, peroxidase, and ascorbate peroxidase play important roles in scavenging for reactive oxygen species ( $\mathrm{Hu}$ et al., 2012). SOD is the initial protective enzyme of the antioxidant defense system in that it stimulates the dismutation of superoxide radical to oxygen and $\mathrm{H}_{2} \mathrm{O}_{2}$ (Sigaud-Kutner et al., 2002). After that, $\mathrm{H}_{2} \mathrm{O}_{2}$ can be scavenged by POD and APX (Jaleel et al., 2009). In this study, the content of hydrogen peroxide increased dramatically under salt stress. The increase was more significant upon the simultaneous application of PTIO and L-NAME while the activity was lower in the SNP regime than in other salt-treated regimes (Fig. 3). This observation suggests that plant suffered extreme damage when exposed to $400 \mathrm{~mm}$ salt stress and that NO involved in the damage. Meloni et al. (2003) reported that under oxidative stress, the generation of ROS triggered the action of antioxidant enzymes in plant. Upon application of SNP to the salt-treated plant, SOD, POD, and APX activities were lower than in other salt-treated plant (Fig. 4). The positive effects of NO might have been due to its ability to scavenge for $\mathrm{O}_{2}^{-}$by reacting with $\mathrm{O}_{2}^{-}$to form $\mathrm{NO}_{2}^{-}$and $\mathrm{NO}_{3}{ }^{-}$(Beligni and Lamattina, 2002). Our results are consistent with those of Seregélyes et al. (2003), who reported that NO plays a role in the suppression of ROS accumulation. However, a slight difference in SOD and APX activities were observed under control condition. The fact may contribute to exogenous NO changed the inner NO signal pathway, thus influenced the SOD and APX activities under control condition.

Assimilation of salt would disturb the ionic balance in plant cells. Such an imbalance can influence the normal metabolism and water status of the plant cells (Hasegawa et al., 2000). In this study, a significant increase of sodium content was observed upon treatment of plant with salt stress (Fig. 6). Also, salinity reduced the uptake of other elements, such as $\mathrm{K}^{+}, \mathrm{Mg}^{2+}$, and $\mathrm{Ca}^{2+}$, a phenomenon that Zhao et al. (2004) and $\mathrm{Hu}$ et al. (2011) also observed. In our study, ion uptake decreased to the lowest level in PTIO plus L-NAME regime as compared with control. On the contrary, exogenously applied SNP alleviated the damage, suggesting that NO was capable of preventing cellular accumulation of $\mathrm{Na}^{+}$to a toxic level under salt stress.

$\mathrm{K}^{+}: \mathrm{Na}^{+}$ratio was reported to be a key factor that influences plant' salt tolerance (Wu and Zou, 2009), and a higher $\mathrm{K}^{+}: \mathrm{Na}^{+}$ ratio was beneficial for a normal cellular function. In this study, a comparison of plant under salt stress, the control, and the NO lacking regimes, revealed that the SNP-treated plant have the highest $\mathrm{K}^{+}: \mathrm{Na}^{+}$ratio. This observation implies that $\mathrm{NO}$ was able to protect plant against salt stress and, hence, enhance the salt tolerance of bermudagrass (Fig. 7A). Our study was in agreement with Zhao et al. (2004), who reported that NO can increase the activity of plasma membrane $\mathrm{H}^{+}$-ATPase, which in turn could increase the uptake of $\mathrm{K}^{+}$, induce high-affinity $\mathrm{K}^{+}$ transporters under salt stress, and help plant adapt to salt stress (Chinnusamy et al., 2005).

$\mathrm{Mg}^{2+}$ plays an important role in plant photosynthesis, which is both a constituent of chlorophyll and an enzyme activator such as in the light activation process of $\mathrm{H}^{+}$-ATPase in chloroplasts (Shahak, 1982). A high $\mathrm{Mg}^{2+}: \mathrm{Na}^{+}$ratio level is essential for the protection of the proper function of chloroplast and may potentially reduce the antagonistic effect of $\mathrm{Na}^{+}(\mathrm{Wu}$ et al., 2010). Our results showed that SNP significantly increased the $\mathrm{Mg}^{2+}: \mathrm{Na}^{+}$ratio under salt stress as compared with other salttreated regimes because of the reduction of $\mathrm{Na}^{+}$and the increase of $\mathrm{Mg}^{2+}$ uptake at the same time (Fig. 7B). The results indicate that NO plays a role in the maintenance of the proper function of photosynthesis, as supported by the changes of $\mathrm{Chl}$ content and OJIP curves under different treatments. 
It is known that calcium serves as the second messenger in signal transduction of plant in responses to stresses (Gong et al., 1998). Geisler et al. (2000) reported that the increased Ca level could improve plant tolerance to salt. In our study, salt stress reduced $\mathrm{Ca}$ and, both the NO scavenger and the NO production inhibitor aggravated the cellular damage. Nonetheless, the NO donor (SNP) significantly prevented the reduction of $\mathrm{Ca}$ under salt stress and helped maintain a high $\mathrm{Ca}^{2+}: \mathrm{Na}^{+}$ratio suggesting that the NO can improve the salt resistance of bermudagrass under salt stress (Fig. 7C). Besides our findings, Zhao et al. (2004) also reported that NO influences the absorption of $\mathrm{Ca}$ and that NO has a protective effect on reed [Phragmites australis (Cav.) Trin. ex Steud.] under salt stress. Overall, NO has the positive effect of maintaining ion homeostasis in bermudagrass subjected to high salinity. However, why $\mathrm{K}$ and $\mathrm{Ca}$ content showed same changing trends when treated with SNP or PTIO plus L-NAME under normal situation remains unclear.

In summary, our study investigated the effect of NO on bermudagrass leaves' response to high salinity stress. In our study, a $400 \mathrm{~mm}$ salinity level caused significant toxicity to bermudagrass. The salt stress reduced the levels of RWC, Chl content, and OJIP curves. The salt stress also caused lipid peroxidation whose manifestations were the increased EL, MDA, and $\mathrm{H}_{2} \mathrm{O}_{2}$ concentration. These adverse effects were pronounced in those indexes after NO inhibitors treatment while NO donor showed positive results. Under salt stress, the level of activity of antioxidant enzymes decreased after treated with SNP suggesting the high efficiency of NO in scavenging for $\mathrm{O}_{2}^{-}$. The changes in element ratios in the bermudagrass under salt stress also suggests the role of NO in the maintenance of ion homeostasis. Our results confirmed the positive effects of NO against salt stress and provided an approach to enhance salt tolerance of bermudagrass, which is a valuable input for land improvement of salinized land in northern China.

\section{Literature Cited}

Abdelly, C., M. Öztürk, M. Ashraf, and C. Grignon. 2008. Biosaline agriculture and high salinity tolerance. Springer Verlag, Basel, Switzerland.

Barrs, H. and P. Weatherley. 1962. A re-examination of the relative turgidity technique for estimating water deficits in leaves. Austral. J. Biol. Sci. 15:413-428.

Beligni, M.V. and L. Lamattina. 2000. Nitric oxide stimulates seed germination and de-etiolation, and inhibits hypocotyl elongation, three light-inducible responses in plants. Planta 210:215-221.

Beligni, M. and L. Lamattina. 2002. Nitric oxide interferes with plant photo-oxidative stress by detoxifying reactive oxygen species. Plant Cell Environ. 25:737-748.

Brugnoli, E. and M. Lauteri. 1991. Effects of salinity on stomatal conductance, photosynthetic capacity, and carbon isotope discrimination of salt-tolerant (Gossypium hirsutum L.) and salt-sensitive (Phaseolus vulgaris L.) C3 non-halophytes. Plant Physiol. 95:628-635. Chance, B. and A.C. Maehly. 1955. Assay catalases and peroxidases. Methods Enzymol. 2:764-768.

Chen, K., L. Chen, J. Fan, and J. Fu. 2013. Alleviation of heat damage to photosystem II by nitric oxide in tall fescue. Photosynth. Res. 116:21-31.

Chinnusamy, V., A. Jagendorf, and J.-K. Zhu. 2005. Understanding and improving salt tolerance in plants. Crop Sci. 45:437-448.

Dhindsa, R., P. Plumb-Dhindsa, and T. Thorpe. 1981. Leaf senescence: Correlated with increased levels of membrane permeability and lipid peroxidation, and decreased levels of superoxide dismutase and catalase. J. Expt. Bot. 32:93-101.
Fan, J., K. Chen, E. Amombo, Z. Hu, L. Chen, and J. Fu. 2015. Physiological and molecular mechanism of nitric oxide (NO) involved in bermudagrass response to cold stress. PLoS One 10:e0132991.

Fan, J., J. Ren, W. Zhu, E. Amombo, J. Fu, and L. Chen. 2014. Antioxidant responses and gene expression in bermudagrass under cold stress. J. Amer. Soc. Hort. Sci. 139:699-705.

Fuller, R.D., E.D. Nelson, and C.J. Richardson. 1982. Reclamation of red mud (bauxite residues) using alkaline-tolerant grasses with organic amendments. J. Environ. Qual. 11:533-539.

Geisler, M., N. Frangne, E. Gomès, E. Martinoia, and M.G. Palmgren. 2000. The ACA4 gene of Arabidopsis encodes a vacuolar membrane calcium pump that improves salt tolerance in yeast. Plant Physiol. 124:1814-1827.

Giannopolitis, C.N. and S.K. Ries. 1977. Superoxide dismutases I. Occurrence in higher plants. Plant Physiol. 59:309-314.

Gong, M., A.H. van der Luit, M.R. Knight, and A.J. Trewavas. 1998. Heat-shock-induced changes in intracellular $\mathrm{Ca}^{2+}$ level in tobacco seedlings in relation to thermotolerance. Plant Physiol. 116:429-437.

Guo, F.-Q., M. Okamoto, and N.M. Crawford. 2003. Identification of a plant nitric oxide synthase gene involved in hormonal signaling. Science 302:100-103.

Hameed, M. and M. Ashraf. 2008. Physiological and biochemical adaptations of Cynodon dactylon (L.) Pers. from the Salt Range (Pakistan) to salinity stress. Flora Morphol. Distrib. Functional Ecol. Plants 203:683-694.

Hasegawa, P.M., R.A. Bressan, J.-K. Zhu, and H.J. Bohnert. 2000. Plant cellular and molecular responses to high salinity. Annu. Rev. Plant Biol. 51:463-499.

Hiscox, J.T. and G. Israelstam. 1979. A method for the extraction of chlorophyll from leaf tissue without maceration. Can. J. Bot. 57:1332-1334.

Hoagland, D.R. and D.I. Arnon. 1950. The water-culture method for growing plants without soil. California Agr. Expt. Sta. Circ. 347.

Hoffman, G., R. Ayers, E. Doering, B. McNeal, and M. Jensen. 1980. Salinity in irrigated agriculture, p. 145-185. In: M.E. Jensen (ed.). Design and operation of farm irrigation systems. Amer. Soc. Agr. Eng., St. Joseph, MI.

Hu, L., H. Li, H. Pang, and J. Fu. 2012. Responses of antioxidant gene, protein and enzymes to salinity stress in two genotypes of perennial ryegrass (Lolium perenne) differing in salt tolerance. J. Plant Physiol. 169:146-156.

Hu, T., H.-Y. Li, X.-Z. Zhang, H.-J. Luo, and J.-M. Fu. 2011. Toxic effect of $\mathrm{NaCl}$ on ion metabolism, antioxidative enzymes and gene expression of perennial ryegrass. Ecotoxicol. Environ. Saf. 74:2050-2056.

Jaleel, C.A., K. Riadh, R. Gopi, P. Manivannan, J. Ines, H.J. Al-Juburi, Z. Chang-Xing, S. Hong-Bo, and R. Panneerselvam. 2009. Antioxidant defense responses: Physiological plasticity in higher plants under abiotic constraints. Acta Physiol. Plant. 31:427-436.

Koca, H., M. Bor, F. Özdemir, and I. Türkan. 2007. The effect of salt stress on lipid peroxidation, antioxidative enzymes and proline content of sesame cultivars. Environ. Expt. Bot. 60:344-351.

Langdale, G. and J. Thomas. 1971. Soil salinity effects on absorption of nitrogen, phosphorus, and protein synthesis by coastal bermudagrass. Agron. J. 63:708-711.

Laspina, N., M. Groppa, M. Tomaro, and M. Benavides. 2005. Nitric oxide protects sunflower leaves against $\mathrm{Cd}$-induced oxidative stress. Plant Sci. 169:323-330.

Lechno, S., E. Zamski, and E. Tel-Or. 1997. Salt stress-induced responses in cucumber plants. J. Plant Physiol. 150:206-211.

Li, L. and R. Qu. 2004. Development of highly regenerable callus lines and biolistic transformation of turf-type common bermudagrass [Cynodon dactylon (L.) Pers.]. Plant Cell Rpt. 22:403-407.

Lutts, S., J. Kinet, and J. Bouharmont. 1996. NaCl-induced senescence in leaves of rice (Oryza sativa L.) cultivars differing in salinity resistance. Ann. Bot. 78:389-398.

Meloni, D.A., M.A. Oliva, C.A. Martinez, and J. Cambraia. 2003. Photosynthesis and activity of superoxide dismutase, peroxidase and 
glutathione reductase in cotton under salt stress. Environ. Expt. Bot. 49:69-76.

Moradi, F. and A.M. Ismail. 2007. Responses of photosynthesis, chlorophyll fluorescence and ROS-scavenging systems to salt stress during seedling and reproductive stages in rice. Ann. Bot. 99:1161-1173.

Neill, S., R. Barros, J. Bright, R. Desikan, J. Hancock, J. Harrison, P. Morris, D. Ribeiro, and I. Wilson. 2008. Nitric oxide, stomatal closure, and abiotic stress. J. Expt. Bot. 59:165-176.

Premachandra, G., H. Saneoka, K. Fujita, and S. Ogata. 1992. leaf water relations, osmotic adjustment, cell membrane stability, epicuticular wax load and growth as affected by increasing water deficits in sorghum. J. Expt. Bot. 43:1569-1576.

Romero-Aranda, R., T. Soria, and J. Cuartero. 2001. Tomato plantwater uptake and plant-water relationships under saline growth conditions. Plant Sci. 160:265-272.

Ruan, H., W. Shen, M. Ye, and L. Xu. 2002. Protective effects of nitric oxide on salt stress-induced oxidative damage to wheat (Triticum aestivum L.) leaves. Chin. Sci. Bull. 47:677-681.

Santa-Cruz, D.M., N.A. Pacienza, A.H. Polizio, K.B. Balestrasse, M. L. Tomaro, and G.G. Yannarelli. 2010. Nitric oxide synthase-like dependent NO production enhances heme oxygenase up-regulation in ultraviolet-B-irradiated soybean plants. Phytochemistry 71: 1700-1707.

Seregélyes, C., B. Barna, J. Hennig, D. Konopka, T.P. Pasternak, N. Lukács, A. Fehér, G.V. Horváth, and D. Dudits. 2003. Phytoglobins can interfere with nitric oxide functions during plant growth and pathogenic responses: A transgenic approach. Plant Sci. 165: 541-550.

Shahak, Y. 1982. The role of $\mathrm{Mg}^{2+}$ in the light activation process of the $\mathrm{H}^{+}$-ATPase in intact chloroplasts. FEBS Lett. 145:223-229.

Shu, S., S.R. Guo, J. Sun, and L.Y. Yuan. 2012. Effects of salt stress on the structure and function of the photosynthetic apparatus in Cucumis sativus and its protection by exogenous putrescine. Physiol. Plant. 146:285-296.

Sigaud-Kutner, T., E. Pinto, O. Okamoto, L. Latorre, and P. Colepicolo. 2002. Changes in superoxide dismutase activity and photosynthetic pigment content during growth of marine phytoplankters in batchcultures. Physiol. Plant. 114:566-571.

Silva, E.N., S.L. Ferreira-Silva, A. de Vasconcelos Fontenele, R.V. Ribeiro, R.A. Viégas, and J.A.G. Silveira. 2010. Photosynthetic changes and protective mechanisms against oxidative damage subjected to isolated and combined drought and heat stresses in Jatropha curcas plants. J. Plant Physiol. 167:1157-1164.

Södergren, E., J. Cederberg, B. Vessby, and S. Basu. 2001. Vitamin E reduces lipid peroxidation in experimental hepatotoxicity in rats. Eur. J. Nutr. 40:10-16.
Tóth, S.Z., G. Schansker, and R.J. Strasser. 2007. A non-invasive assay of the plastoquinone pool redox state based on the OJIP-transient. Photosynth. Res. 93:193-203.

Tsimilli-Michael, M. and R.J. Strasser. 2008. Experimental resolution and theoretical complexity determine the amount of information extractable from the chlorophyll fluorescence transient OJIP, p. 697-701. In: J. Allen, E. Gantt, J. Golbeck, and B. Osmond (eds.). Photosynthesis. Energy from the sun. Springer, Dordrecht, The Netherlands.

Uchida, A., A.T. Jagendorf, T. Hibino, T. Takabe, and T. Takabe. 2002. Effects of hydrogen peroxide and nitric oxide on both salt and heat stress tolerance in rice. Plant Sci. 163:515-523.

Whitlow, T.H., N.L. Bassuk, T.G. Ranney, and D.L. Reicher. 1992. An improved method for using electrolyte leakage to assess membrane competence in plant tissues. Plant Physiol. 98:198-205.

Wildt, J., D. Kley, A. Rockel, P. Rockel, and H. Segschneider. 1997. Emission of NO from several higher plant species. J. Geophys. Res. Atmos. 102:5919-5927.

Wu, Q.-S., Y.-N. Zou, and X.-H. He. 2010. Contributions of arbuscular mycorrhizal fungi to growth, photosynthesis, root morphology and ionic balance of citrus seedlings under salt stress. Acta Physiol. Plant. 32:297-304

Wu, Q.S. and Y.N. Zou. 2009. Adaptive responses of birch-leaved pear (Pyrus betulaefolia) seedlings to salinity stress. Not. Bot. Horti Agrobot. Cluj-Napoca 37:133.

Xie, J., Y. Li, C. Zhai, C. Li, and Z. La. 2009. CO2 absorption by alkaline soils and its implication to the global carbon cycle. Environ. Geol. 56:953-961.

Xu, J., H. Yin, Y. Li, and X. Liu. 2010a. Nitric oxide is associated with long-term zinc tolerance in Solanum nigrum. Plant Physiol. 154:1319-1334

Xu, Y., X. Sun, J. Jin, and H. Zhou. 2010b. Protective effect of nitric oxide on light-induced oxidative damage in leaves of tall fescue. J. Plant Physiol. 167:512-518.

Ya'acov, Y.L., R.B. Wills, and V.V.-V. Ku. 1998. Evidence for the function of the free radical gas - nitric oxide (NO•) - as an endogenous maturation and senescence regulating factor in higher plants. Plant Physiol. Biochem. 36:825-833.

Zhang, D. and W. Shijie. 2001. Mechanism of freeze-thaw action in the process of soil salinization in northeast China. Environ. Geol. 41:96-100.

Zhao, F. and P. Qin. 2004. Protective effect of exogenous polyamines on root tonoplast function against salt stress in barley seedlings. Plant Growth Regulat. 42:97-103.

Zhao, L., F. Zhang, J. Guo, Y. Yang, B. Li, and L. Zhang. 2004. Nitric oxide functions as a signal in salt resistance in the calluses from two ecotypes of reed. Plant Physiol. 134:849-857. 